\title{
Comparative trial of sulphasalazine and oral sodium cromoglycate in the maintenance of remission in ulcerative colitis
}

\author{
M. W. DRONFIELD AND M. J. S. LANGMAN \\ From the Department of Therapeutics, City Hospital, Nottingham
}

SUMMARY Patients with ulcerative colitis in remission were randomly allocated to treatment with sulphasalazine ( $2 \mathrm{~g} /$ day) or oral sodium cromoglycate $(160 \mathrm{mg} /$ day or $2 \mathrm{~g} /$ day $)$, and the relapse rates in these treatment groups were compared during continued treatment for one year. The percentage cumulative relapse rate after 12 months' treatment was $30 \%$ in the 33 patients treated with sulphasalazine compared with $71 \%$ in the 25 treated with high dose sodium cromoglycate, a highly significant difference $(\mathbf{P}<0.01)$. Patients allocated low dose sodium cromoglycate were only treated for a maximum of six months, and the relapse rate in these 12 patients was similar to that in patients on the high dose. These results suggest that oral sodium cromoglycate is considerably less effective than sulphasalazine in maintaining remission, and by analogy with results in other trials may be no more effective than placebo tablets.

Ulcerative colitis is a condition that is usually characterised by periods of remission and relapse, and four out of every five patients who have just recovered from a relapse can anticipate a further attack within the next year if maintenance treatment is not prescribed (Edwards and Truelove, 1963). This relapse rate can be reduced by sulphasalazine (SSZ) $2 \mathrm{~g}$ daily (Misiewicz et al., 1965), and patients will continue to benefit from maintenance SSZ treatment for several years after their last relapse (Dissanayake and Truelove, 1973). Some patients, however, do not respond to SSZ treatment and a few cannot tolerate it because of side-effects. An alternative effective maintenance treatment would therefore be very useful in the management of these patients.

A recent trial has shown that sodium cromoglycate (SCG) taken simultaneously by mouth and retention enema improves the symptoms and sigmoidoscopic appearances in some patients with chronic active proctitis (Heatley et al., 1975), and a further study showed some benefit of orally administered SCG in a dose of $2 \mathrm{~g}$ daily when administered to patients with proctocolitis over a six-month period (Mani et al., 1976).

In bronchial asthma SCG is used to prevent attacks rather than to shorten them. It seems likely, therefore, that if it is effective in ulcerative colitis it will

Received for publication 21 August 1978 prolong remission, and we have therefore compared it with SSZ in a controlled clinical trial in patients with quiescent ulcerative colitis.

\section{Methods}

\section{PATIENTS}

Fifty-four patients with ulcerative proctitis or proctocolitis, as judged by clinical, sigmoidoscopic, radiological, and histological criteria, were admitted to the trial, and all had had a symptomatic attack of their disease within the past 12 months. The patients were all in remission at the start of the trial as judged by symptoms and sigmoidoscopic appearance, and were on no treatment other than maintenance SSZ.

\section{TREATMENT ALLOCATION}

Treatment was allocated by a prearranged randomised schedule to either SSZ, 2 g (four tablets) daily, or SCG, $2 \mathrm{~g}$ (10 tablets) daily in divided doses. Early in the study, before this high dose SCG became available, patients who were allocated SCG were given $160 \mathrm{mg}$ (eight capsules) daily, and if relapse had not occurred treatment was switched to the high dose preparation when it became available. Tablets of SCG and SSZ differed in appearance and the trial was consequently single-blind: physicians seeing the patients therefore avoided discussing the nature of the treatments in use. 
CONDUCT OF TRIAL

After the initial visit patients were seen and assessed two-monthly, sigmoidoscopy and rectal biopsy being performed at the beginning and end of the trial, and at other times if symptoms developed. At each visit the pharmacist checked that the patients were taking the correct number of tablets. Treatment was continued for 12 months or until relapse occurred, a relapse being defined as a return of symptoms due to active ulcerative colitis or proctitis that required additional treatment. If relapse occurred, the patient was withdrawn from the trial and treated as indicated clinically, and when remission was again achieved some patients were crossed over to the alternative maintenance treatment and followed up for a further year or until a further relapse.

Side-effects were recorded if complained of spontaneously, and blood was taken at the beginning of the trial and after two, six, and 12 months' treatment for haematological and biochemical screening.

\section{Results}

Thirty-four patients were treated with SSZ, 26 with high dose SCG, and 12 with low dose SCG. Two patients were withdrawn from the trial; one who was allocated SSZ and failed to attend for follow-up, and one who was unable to tolerate the high dose SCG allocated because it caused intolerable urgency of defaecation which developed again when treatment was reintroduced. Treatment was otherwise well tolerated, there being no withdrawals because of side-effects in the SSZ treated patients, in part because patients with a history of intolerance to SSZ were excluded from the study.

Nine of the SSZ treated patients and four of the high dose SCG treated patients were crossed over in the trial after relapses on the alternative treatment, and a further five patients were switched from low to high dose SCG when the latter became available.

All the patients were followed up until relapse or the completion of 12 months' treatment, except for one patient on high dose SCG and five on SSZ who had six to eight months' treatment only.

\section{COMPARABILITY OF PATIENTS}

The clinical features of the patients in the three treatment groups are shown in Table 1. They were similar in age and sex distribution, and in the severity of their disease as judged by the total duration of symptoms, the number of previous symtomatic attacks, and the extent of the disease on barium enema. There was also little difference in the mean symptom-free period since the last attack and in the treatment the patients had received over the preceding six months.

\section{RELAPSES}

The effecti eness of treatment was measured by comparing the relapse rates in the treatment groups (Table 2). Relapse was more common on SCG than SSZ treatment, seven of the 12 patients on low dose SCG relapsing and 16 of 25 on high dose SCG

Table 1 Comparability of patients in three treatment groups

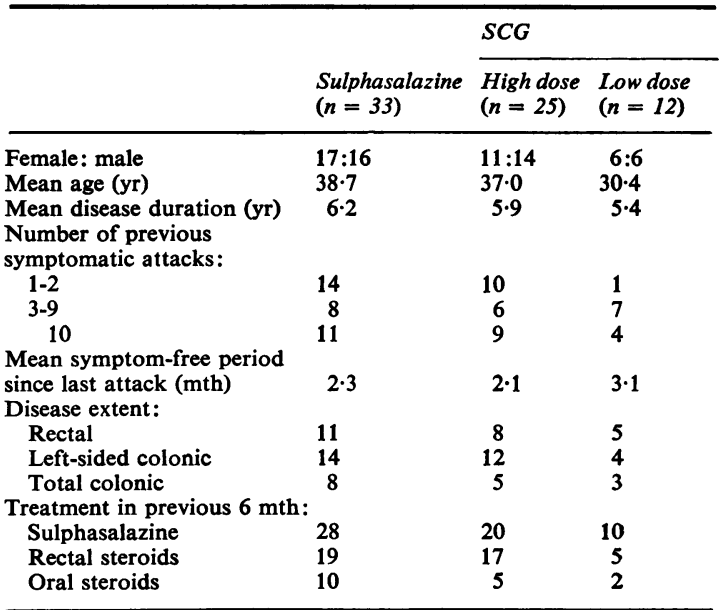

Table 2 Relapses in three treatment groups

\begin{tabular}{|c|c|c|c|c|c|c|}
\hline \multirow[t]{3}{*}{ Months treated } & \multirow{2}{*}{\multicolumn{2}{|c|}{ Sulphasalazine }} & \multicolumn{4}{|l|}{$S C G$} \\
\hline & & & \multicolumn{2}{|l|}{ High dose } & \multicolumn{2}{|l|}{ Low dose } \\
\hline & Patients treated & Relapses & Patients treated & Relapses & Patients treated & Relapses \\
\hline $\begin{array}{c}0-2 \\
2-4 \\
4-6 \\
6-8 \\
8-10 \\
10-12\end{array}$ & $\begin{array}{l}33 \\
29 \\
24 \\
23 \\
18 \\
18\end{array}$ & $\begin{array}{l}4 \\
5 \\
0 \\
1 \\
0 \\
0\end{array}$ & $\begin{array}{l}20 \\
14 \\
13 \\
12 \\
12 \\
10\end{array}$ & $\begin{array}{l}8 \\
2 \\
2 \\
0 \\
2 \\
2\end{array}$ & $\begin{array}{r}12 \\
7 \\
3 \\
- \\
-\end{array}$ & $\begin{array}{l}3 \\
3 \\
1 \\
- \\
-\end{array}$ \\
\hline Totals & 33 & $10 *$ & 25 & $16^{*}$ & 12 & 7 \\
\hline
\end{tabular}

$*\left(x^{2}=7 \cdot 18, \mathrm{df}=1, \mathrm{P}<0.01\right)$. 
compared with 10 of 33 on SSZ. Most relapses occurred early in the trial, particularly in SSZ treated patients, only one of whom relapsed after four menths of treatment. The relapse rate on high dose SCG was substantially higher, particularly later in the trial, six relapses occurring after the fourth month

There was no significant difference between the relapse rates on high and low dose SCG, but the difference between relapse rates on SSZ and high dose SCG was highly significant $(P<0.01)$ as calculated by the Logrank test (Peto et al., 1977).

Because patients have not all been followed-up for a year and because some patients were switched from low to high dose SCG during the first six months of the trial, comparison of relapse rates is facilitated by calculating the percentage cumulative relapse rate for each two month treatment period, as shown in the Figure, which demonstrates clearly the wide difference in relapse rates in patients treated with SSZ on the one hand and high and low dose SCG on the other.

\section{SAFETY}

Blood was taken from most patients at the beginning of the trial and after two, six, and 12 months for haemoglobin level, white cell count and platelet count, and for the following biochemical measurements: urea, creatinine, uric acid, bilirubin, alkaline phosphatase, gamma glutamyl transpeptidase, and glutamic pyruvate transaminase. No consistent abnormality attributable to treatment occurred in any of them.

\section{Discussion}

We have confirmed in this trial that SSZ is strikingly effective in reducing the relapse rate in patients with ulcerative colitis, but that oral SCG in both high and low dosage is substantially less effective. The high dose SCG patients received $2 \mathrm{~g}$ of SCG daily, an arbitrarily chosen amount which is considerably greater than the $800 \mathrm{mg}$ daily that is currently recommended by the manufacturers of SCG for the treatment of ulcerative colitis, and it seems unlikely that higher doses will be effective, as we were unable to find any difference in relapse rates between patients on this high dose and those on just $160 \mathrm{mg}$ SCG daily. The difference between the relapse rates on SSZ and high dose SCG was marked from the second month of treatment onwards, a difference that cannot reasonably be attributed to methodological shortcomings in the conduct of the trial, such as our failure to use identical SSZ and SCG tablets. It is not possible to say with certainty whether or not SCG has any effect in preventing relapse, as no placebo treated group was included; a trial including such a group would be unethical, as SSZ is known to be effective. However, the relapse rate of $71 \%$ at 12 months in our patients on high dose SCG is very similar to the $75 \%$ relapse rate in placebo treated patients in a previous similar trial (Misiewicz et al., 1965), and it is likely therefore that SCG taken in a dose of $2 \mathrm{~g}$ /day by mouth does not prolong remission in ulcerative colitis.

There is little convincing evidence from other studies that SCG taken by mouth is effective in

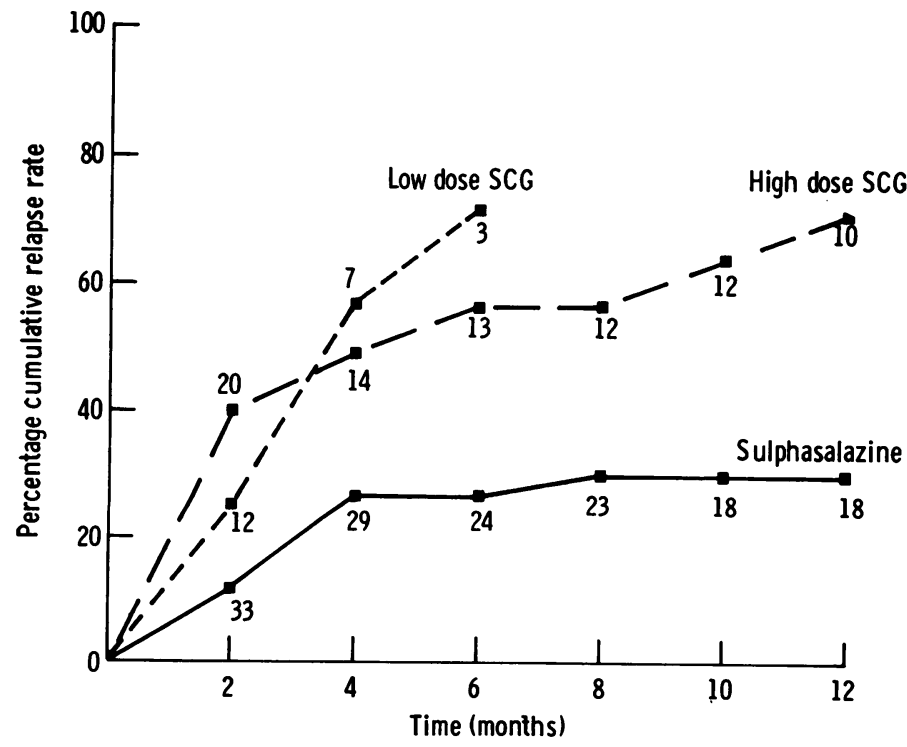

Figure Sodium cromoglycate and sulphasalazine: cumulative relapse rate. Numbers: patients evaluated at each two-monthly visit. 
ulcerative colitis. Mani et al. (1976) reported improvement in the patients' sense of wellbeing and sigmoidoscopic appearance when treated with SCG 2 g/day by mouth over six months, but only 12 patients were studied, and there was no effect on symptoms of rectal bleeding and diarrhoea. In another recent sudy SCG in a dose of $800 \mathrm{mg} /$ day taken orally was found to be ineffective in a double-blind placebo-controlled crossover trial in 26 patients with ulcerative colitis who had not responded to conventional treatment and in most of whom SSZ and cortiscosteroids were continued (Gould et al., 1978). The remaining evidence that SCG is effective is from a trial in which it was administered both orally and rectally to patients with chronic active proctitis (Heatley et al., 1975).

As SCG taken by mouth is excreted almost entirely unchanged in the faeces, any effect it might have on the colonic and rectal mucosa is likely to be topical. It could be, therefore, that SCG is effective in ulcerative protocolitis but that there is an insufficient concentration of the drug in the colon when it is administered by mouth. Future trials of this compound should, therefore, include its rectal administration, although this is a form of therapy that is unlikely to be accepted by patients for the long-term maintenance of remission. An alternative might be a systemically active cromone, when and if such a compound becomes available.

We are grateful to Fisons Pharmaceuticals Ltd, for supplying the sodium cromoglycate tablets and for financial support, to Mrs Janet Watkinson for allocating treatment and checking patient compliance, and to Dr G. D. Bell and Dr M. B. McIllmurray for reviewing some of the patients.

\section{References}

Dissanayake, A. S., and Truelove, S. C. (1973). A controlled therapeutic trial of long-term maintenance treatment of ulcerative colitis with sulphasalazine (Salazopyrin). Gut,14, 923-926.

Edwards, F. C., and Truelove, S. C. (1963). The course and prognosis of ulcerative colitis. Part II. Long-term prognosis. Gut, 4, 309-315.

Gould, S. R., Buckell, N. A., Day, D. W., Edwards, A. M., and Lennard-Jones, J. E. (1978). Controlled trial of disodium cromoglycate in chronic persistent colitis (Abstract). Gut, 19A, 444.

Heatley, R. V., Calcraft, B. J., Rhodes, J., Owen, E., and Evans, B. K. (1975). Disodium cromoglycate in the treatment of chronic proctitis. Gut, 16, 559-563.

Mani, V., Lloyd, G., Green, F. H. Y., Fox, H., and Turnberg, L. A. (1976). Treatment of ulcerative colitis with oral disodium cromoglycate. Lancet, 1, 439-441.

Misiewicz, J. J., Lennard Jones, J. E., Connell, A. M., Baron, J. H., and Jones, F. A. (1965). Controlled trial of sulphasalazine in maintenance therapy for ulcerative colitis. Lancet, 1, 185-188.

Peto, R., Pike, M. C., Armitage, P., Breslow, N. E., Cox, D. R , Howard, S. V., Mantel, N., McPherson, K., Peto, J., and Smith, P. G. (1977). Design and analysis of randomized clinical trials requiring prolonged observation of each patient. II. Analysis and examples. British Journal of Cancer, 35, 1-39. 